\title{
Cable Testing for Fermilab's High Field Magnets Using Small Racetrack Coils
}

\author{
S. Feher, G. Ambrosio, N. Andreev, E. Barzi, B. Bordini, R. Bossert, R. Carcagno, V.I. Kashikhin, \\ V. V. Kashikhin, M.J. Lamm, I. Novitski, D. Orris, Y. Pischalnikov，C. Sylvester，M. Tartaglia, \\ R. Yamada, A.V. Zlobin
}

\begin{abstract}
As part of the High Field Magnet program at Fermilab simple magnets have been designed utilizing small racetrack coils based on a sound mechanical structure and bladder technique developed by LBNL. Two of these magnets have been built in order to test $\mathrm{Nb}_{3} \mathrm{Sn}$ cables used in cos-theta dipole models. The powder-in-tube strand based cable exhibited excellent performance. It reached its critical current limit within 14 quenches. Modified jelly roll strand based cable performance was limited by magnetic instabilities at low fields as previously tested dipole models which used similar cable.
\end{abstract}

Index Terms-Accelerator, Magnet, High Field Dipole, $\mathrm{Nb}_{3} \mathrm{Sn}$

\section{INTRODUCTION}

$\mathrm{F}$ ERMILAB is working on a new generation of superconducting magnets for present and future accelerators. These magnets utilize several different Rutherford-type cable designs made of state-of-the-art $\mathrm{Nb}_{3} \mathrm{Sn}$ strands. Strand and cable tests are important aspects of the magnet R\&D program. Fermilab has designed small two-layer racetracks arranged in common coil configuration which were packaged into subscale racetrack (SR) magnets based on a sound mechanical structure and bladder technique developed by LBNL[1]-[2]. The main goal of this work is to test full-size $\mathrm{Nb}_{3} \mathrm{Sn}$ cables using compact coil systems that implement $\mathrm{Nb}_{3} \mathrm{Sn}$ magnet technology and real cable operating conditions. With such coils, two types of cable, including those used in Fermilab's cos-theta dipole models, were successfully tested in two subscale magnets (SR01 and SR02). These cables were made out of powder-in-tube (PIT) and modified jelly roll

TABLE I

MAGNET DESIGN PARAMETERS

\begin{tabular}{lc}
\hline \multicolumn{1}{c}{ Parameter } & Value \\
\hline \hline B MAX, T & 11.06 \\
I max, kA & 28.12 \\
Aperture, mm & 2 \\
Coil area, $\mathrm{cm}^{2}$ & 6.05 \\
Number of turns per coil & 13 \\
Iron yoke OD, mm & 215 \\
Stored energy $@ 11 \mathrm{~T}, \mathrm{~kJ} / \mathrm{m}$ & 19.05
\end{tabular}

Manuscript received October 5, 2004. This work was supported in part by the U.S. Department Energy.

Authors are with the Fermi National Accelerator Laboratory, Batavia, Il 60510 USA.
(MJR) strands $1.0 \mathrm{~mm}$ in diameter featuring high critical current density and an ample range of effective filament sizes ( 50 and 110 microns respectively). This paper describes the design and fabrication of the two racetrack magnets, as well as their instrumentation and the test procedures applied at the Fermilab's Vertical Magnet Test Facility. The results of these tests are reported and discussed.

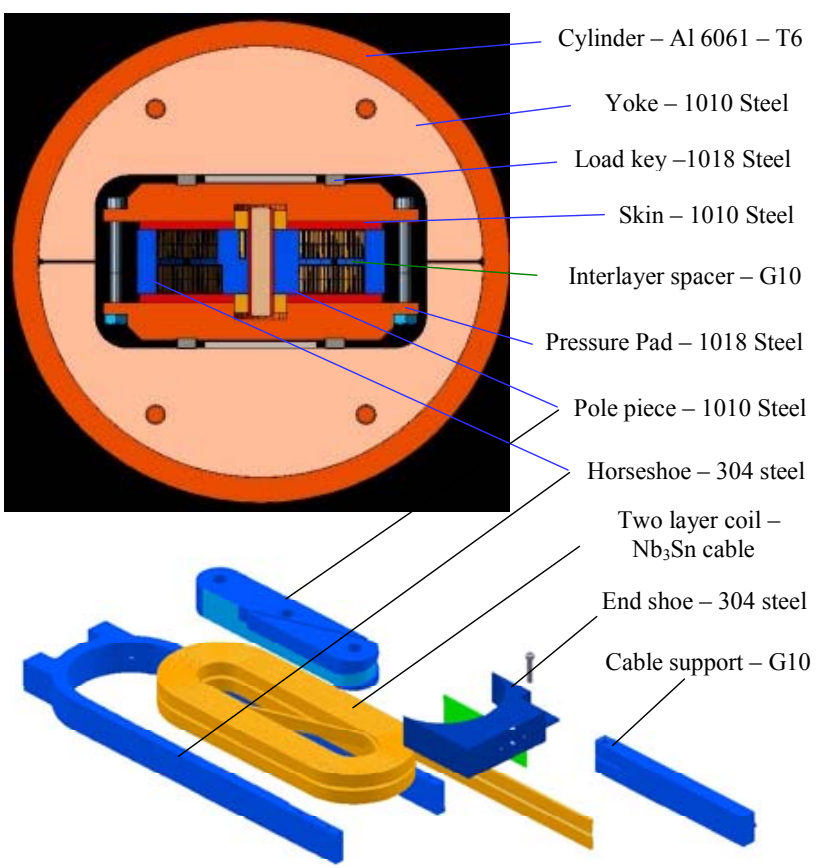

Fig. 1. General layout of the Subscale Racetrack magnet.

\section{SR01 AND SR02 MAGNET Design AND FABRICATION}

\section{A. $\quad$ Racetrack design and parameters}

The design of small racetrack magnets SR01 and SR02 developed at Fermilab is based on the mechanical structure developed at LBNL for subscale models, but utilizes full-size cables used in Fermilab's high field magnets which have approximately twice the width. A general layout, showing the internal magnet components, is shown in Fig. 1. Table I contains the magnet general design parameters. 


\section{B. Strand and cable}

The cable was manufactured at Fermilab, using two different types of stand: $1 \mathrm{~mm}$ diameter PIT strands manufactured by Shape Metal Innovation and $1 \mathrm{~mm}$ diameter MJR strands manufactured by Oxford. Both cables were rectangular in cross section (no keystone), contained 28 strands, and had overall dimensions of $14.2 \mathrm{~mm} \times 1.84 \mathrm{~mm}$ for the PIT cable and $13.95 \mathrm{~mm} \times 1.95 \mathrm{~mm}$ for the MJR cable, respectively. Before insulating, the cable was heat-treated at $200^{\circ} \mathrm{C}$ for 30 minutes to reduce residual stresses incurred during the strand and cable manufacturing processes.

Cable insulation consisted of $0.250 \mathrm{~mm}$ thick and $13 \mathrm{~mm}$ wide S-2 Fiberglass tape, spiral wrapped onto the cable with a $3.3 \mathrm{~mm}$ overlap. To improve the stiffness of the insulation, an inorganic binder, CTD-1008®, was applied to the tape and cured at $80^{\circ} \mathrm{C}$ for 30 minutes before wrapping onto the cable.

TABLE II

STRAND PARAMETERS

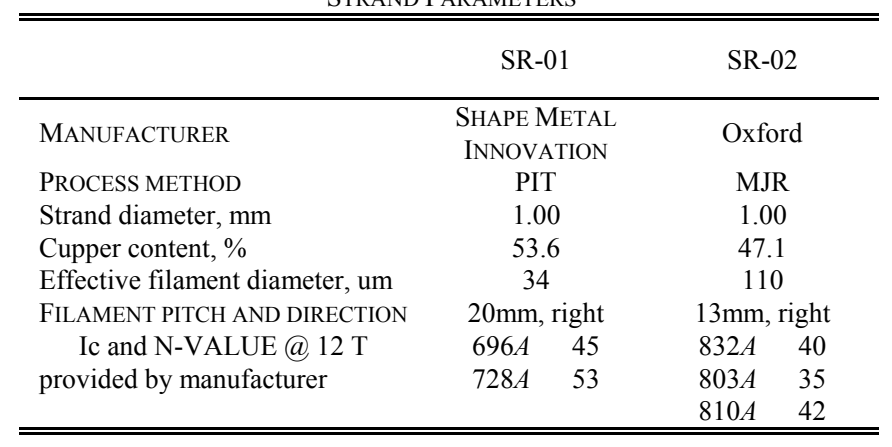

TABLE III

CABLE PARAMETERS

\begin{tabular}{|c|c|c|}
\hline & SR-01 & SR-02 \\
\hline MATERIAL & PIT & MJR \\
\hline Cable type & Rutherford & Rutherford \\
\hline Dimensions, $\mathrm{mm}$ & $14.20 \times 1.84$ & $13.85 \times 1.95$ \\
\hline Strand diameter, $\mathrm{mm}$ & 1.00 & 1.00 \\
\hline Number of strands & 28 & 28 \\
\hline Strand Jc by design (12 T $4.2 \mathrm{~K})$ & 2000 & 2000 \\
\hline $\mathrm{Cu} /$ Non_Cu by design & 0.85 & 0.85 \\
\hline Keystone angle & 0 & 0 \\
\hline
\end{tabular}

Strand and cable parameters are summarized in Table II and Table III.

\section{Coil fabrication}

Both PIT and MJR coils were fabricated using the same procedures. To determine an estimate of the coil size after winding, stacks of both bare and insulated cable were measured at a range of pressures. These measurements were then used to determine the cavity size to be used in the reaction fixture during the coil heat treatment. The reaction fixture cavity size was shimmed to a thickness based on the insulated cable data taken at a pressure of approximately 14 MPa.

The two-layer, 26-turn (13 turns in each layer) racetrack coil was wound around an iron pole piece (as shown in Fig.
1.) with winding tension of $30 \mathrm{~kg}$. Each coil layer required 6.5 $\mathrm{m}$ of cable.

Interlayer insulation, consisted of 2 layers of $1 \mathrm{~mm}$ thick spacer of S-2 glass. The spacer was fabricated at Fermilab by compressing 10 layers of thin S-2 glass cloth, filling with inorganic binder, and curing at $150^{\circ} \mathrm{C}$ for 30 minutes.

Ground insulation was applied in a two-step process. First, a temporary layer of ceramic cloth was used during the coil reaction. This cloth filled the area between the coil and the reaction fixture and provided tiny channels for Argon flow during reaction. This layer was removed after reaction and replaced with a combination of sheets of S-2 fiberglass material and G-10 that covered the coils during the epoxy impregnation and became a permanent part of the magnet.

Heat treatment was performed inside a reaction retort at Argon atmosphere at $660^{\circ} \mathrm{C}$ for both MJR and PIT coils. Specific reaction cycles varied for the two materials. For the PIT coils, the temperature was increased from room temperature by $25^{\circ} \mathrm{C} /$ hour to $660^{\circ} \mathrm{C}$ and remained at $660^{\circ} \mathrm{C}$ for 170 hours. For the MJR coils, a multistage reaction cycle was used. The temperature first was increased from room temperature by $25^{\circ} \mathrm{C} /$ hour to $210^{\circ} \mathrm{C}$ and remained at $210^{\circ} \mathrm{C}$ for 100 hours, then it was increased by $50^{\circ} \mathrm{C} /$ hour to $340^{\circ} \mathrm{C}$ and remained at $340^{\circ} \mathrm{C}$ for 48 hours, and finally it was increased by $75^{\circ} \mathrm{C} /$ hour to $660^{\circ} \mathrm{C}$ and remained at $660^{\circ} \mathrm{C}$ for 72 hours before cooling.

The splices were made after reaction. Each $\mathrm{Nb}_{3} \mathrm{Sn}$ lead was sandwiched between two NbTi cables. Leads from both layers were soldered simultaneously in a special fixture made for this application. The splices were insulated with $0.05 \mathrm{~mm}$ Kapton. After the splices were made, six voltage taps were attached. One voltage tap was added at the coil midpoint later, after impregnation.

The coil was impregnated in an aluminum fixture with CTD-101® epoxy at a vacuum of approximately $75 \mu$ bar. The combined thickness of the iron pole, the coil, the end shoe and the horseshoe needs to be controlled to prevent the brittle conductor from over-compression. This was achieved by shimming the coil and the horseshoe with Kapton ${ }^{\circledR}$ sheets. Before shimming, tests on the assembly were done by bolting it together with Fuji film applied to the critical surfaces to check the pressure distribution. Results show that the pole island and the horseshoe are the most heavily loaded parts.

The area of maximum stress concentration was near the inner to outer layer transition at the pole. Due to the deformations created by bending the cable from inner to outer layer, a wave forms in the cable in the transverse direction, which continues to be evident for several turns. Where the wave crests, the cable tries to move out of its designated layer, causing intermittent high loading along the thin edge.

\section{Racetrack assembly and mechanical measurements}

After impregnation, the completed coil block was placed into a pre-assembled yoke structure with a bladder positioned between the coils and the yoke. The inflated bladder stretched the aluminum cylinder and compressed the coil block. Keys were inserted, which maintained load on the coil after the bladder had been deflated and removed. The coil stress was approximately $30 \mathrm{MPa}$ when the cylinder was loaded to 270 
MPa. Maximum stress in the various magnet components at different stages calculated with ANSYS is shown in Table IV. TABLE IV

STRESSES IN DIFFERENT COMPONENTS (MPA)

\begin{tabular}{lcccc}
\hline \hline & Bladders & $300 \mathrm{~K}$ & $4.2 \mathrm{~K}$ & $\mathrm{Bmax}$ \\
\hline Al Cylinder & 270 & 170 & 420 & 420 \\
Nb3Sn Coil & 30 & 16 & 20 & 40 \\
Iron Yoke & 360 & 160 & 480 & 480 \\
\hline \hline
\end{tabular}

A total of eight resistive strain gauges were installed on the aluminum cylinder for the purpose of measuring coil preload, as shown in Figure 2. Six of them were located at the middle of the magnet. Four are positioned to measure azimuthal stress: 1A-a, 1B-a, 1D-a, 1E-a. Two are positioned to measure longitudinal stress: $1 \mathrm{G}-1$ and $1 \mathrm{H}-1$. 1A-a and 1D-a are the midplane-azimuthal gauges, and $1 \mathrm{~B}-\mathrm{a}$ and $1 \mathrm{E}-\mathrm{a}$ are the pole-azimuthal gauges. Gauges $1 \mathrm{C}$ and $1 \mathrm{~F}$ were located on the edge to measure the average stress across the cylinder thickness.

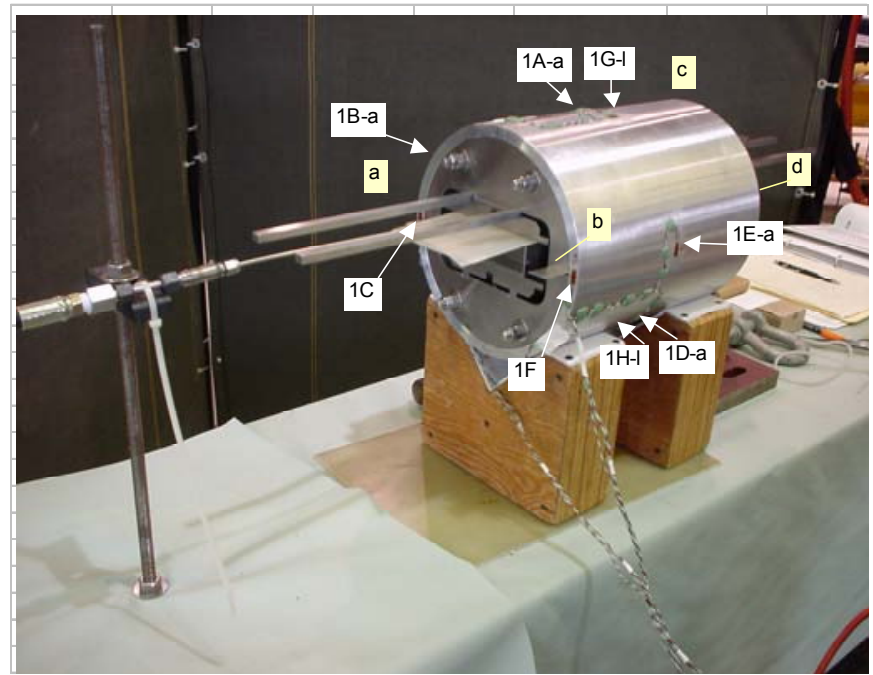

Fig. 2. Strain gauge locations are shown.

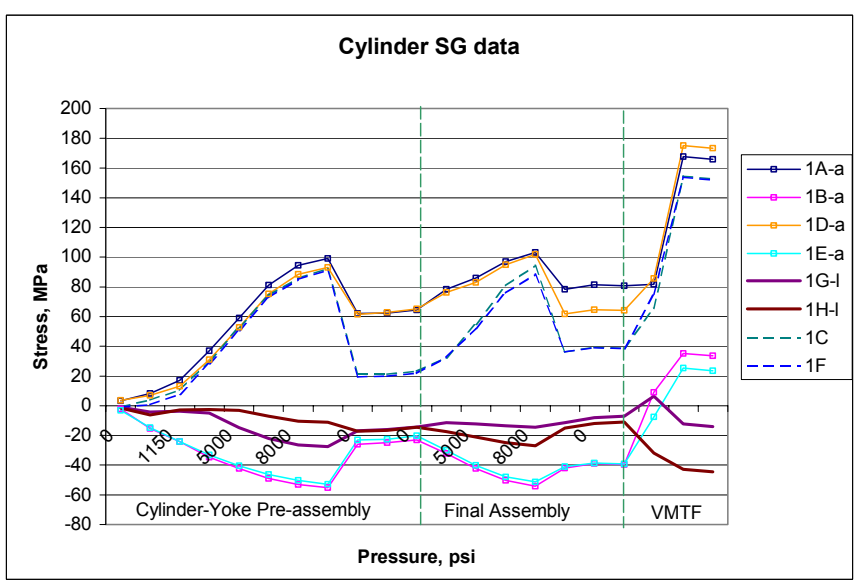

Fig. 3. Summary of the stress analysis is shown (better plot).

There were two assembly steps: cylinder-yoke preassembly and final assembly. During these steps, strain gauge data were taken and the outside diameter of the aluminum cylinder is monitored using a micrometer and pi-tape. Strain Gauge data are shown in Fig. 3. Gauges 1A-a and 1D-a were chosen as the main process indicators since they are located in the area which has the most uniform cylinder deformation. The maximum load reached on the shell was $103 \mathrm{MPa}$. Spring back after the keying process is completed is $25-30 \%$.

\section{Test RESUlts}

SR01 with PIT cable and SR02 with MJR cable were tested at Fermilab's Vertical Magnet Test Facility (VMTF) [3] which is capable of testing up to $4.5 \mathrm{~m}$ long superconducting magnets at 0-30 kA current range. These racetracks were instrumented with a minimal number of voltage taps. Two voltage taps were soldered to the leads and one of them to the center of the magnet to make two half coil voltage segments for protection. Two additional voltage taps were soldered right next to the NbTi side of the splices so splice measurements could be made. In order to be able to initiate a quench, a spot heater was installed on one of the coils. This heater was useful to check that the magnet protection circuits were functional before the magnet was fully energized.

\section{A. SR01 quench history}

SR01 was tested in February - March 2004. After the magnet was cooled down to $4.5 \mathrm{~K}$ a quench test was performed. The history of the quench test is summarized in Fig. 4. The first quench of the magnet occurred at relatively high current of $19292 A$. This current was already much higher than any previously built $\mathrm{Nb}_{3} \mathrm{Sn}$ magnet at Fermilab. It took 14 more quenches at $20 \mathrm{~A} / \mathrm{sec}$ ramp rate to train the magnet. The maximum current value was at $23713 A$. This value is consistent with the calculated critical current value estimated by measuring critical current of strands at the Fermilab Short Sample Test Facility (SSTF) taking into account additional degradation of PIT cable due to its sensitivity to transverse pressure [4].

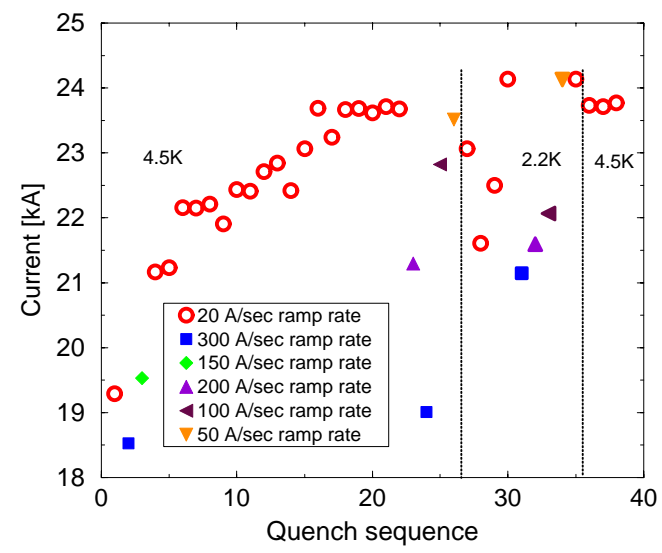

Fig. 4. Quench history of SR01.

In order to expose the magnet to larger Lorentz forces the magnet was cooled down to $2.2 \mathrm{~K}$ and quenched several times. Both low and high ramp rate quenches exhibited erratic behavior showing no sign of any training. Although the magnet quench current was much lower that what one would expect from any reasonable temperature parameterization of the quench current, we were able to increase the Lorentz 
forces within the magnet. So if the magnet was not trained at $4.5 \mathrm{~K}$ we should have accelerated its training. On the other hand if the magnet reached its critical limit value the quench current should not show any improvement once it is warmed up again to $4.5 \mathrm{~K}$. From Fig. 4 . one can conclude that the magnet quench current remained the same consequently the magnet reached its critical current limit.

\section{B. SR02 quench history}

SR02 was tested in June 2004. Training of this magnet was much longer than SR01. It took more than 20 quenches to reach a quench plateau (see Fig. 5.). However, this plateau was not very smooth indicating that the magnet didn't reach its critical current limit. After ramp rate studies we cooled the magnet down to $2.2 \mathrm{~K}$ and quenched the magnet 11 times. The quench current was erratic and lower than what was achieved at $4.5 \mathrm{~K}$. After warming up the magnet again to $4.5 \mathrm{~K}$ the magnet quench behavior remained erratic. Magnet quench performance is limited by low field quenches which is consistent with theoretical and experimental studies of magnetic instabilities in $\mathrm{Nb}_{3} \mathrm{Sn}$ state of the art strands and cables performed at Fermilab [5-8] .

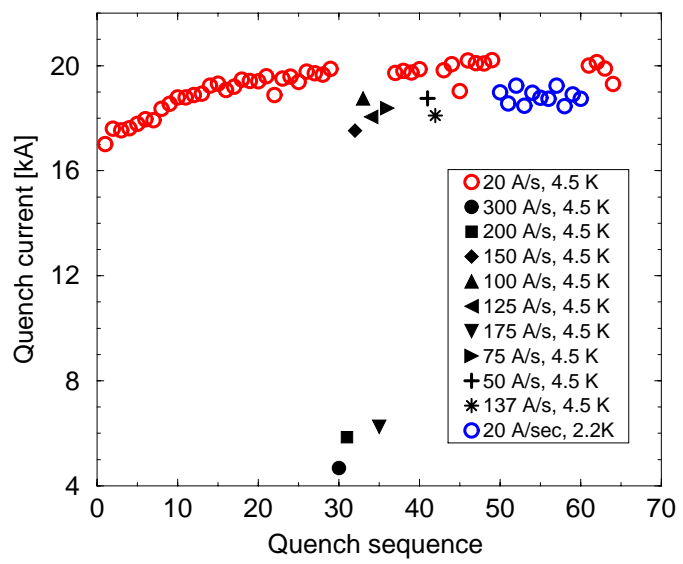

Fig. 5. SR02 quench history.

\section{Ramp rate studies}

After training ramp rate dependence studies were performed (see Fig. 6.). The quench current as a function of the ramp rate for SR01 follows a smooth curve indicating that the magnet has no other limitation than its critical current value. Quench current as a function of the ramp rate for SR02 however, was not a smooth curve.

TABLE V

SPLICE RESISTANCES AND RRR VALUES

\begin{tabular}{lccc}
\hline \hline & $\begin{array}{c}\text { Lead splice 1 } \\
\text { Resistance }[\mathrm{n} \Omega]\end{array}$ & $\begin{array}{c}\text { Lead splice 2 } \\
\text { Resistance }[\mathrm{n} \Omega]\end{array}$ & RRR \\
\hline SR01 & 0.76 & 0.80 & 129 \\
SR02 & 0.57 & 0.67 & 125 \\
\hline \hline
\end{tabular}

The error of the resistance measurement is about $\pm 0.04 \mathrm{n} \Omega$

The error of the RRR value is about \pm 5

\section{Splice resistance measurements}

Both SR01 and SR02 splice resistance values (see Table V) are small enough to ensure us that quench current limitation of SR02 is very unlikely to be associated with splice manufacturing issues.

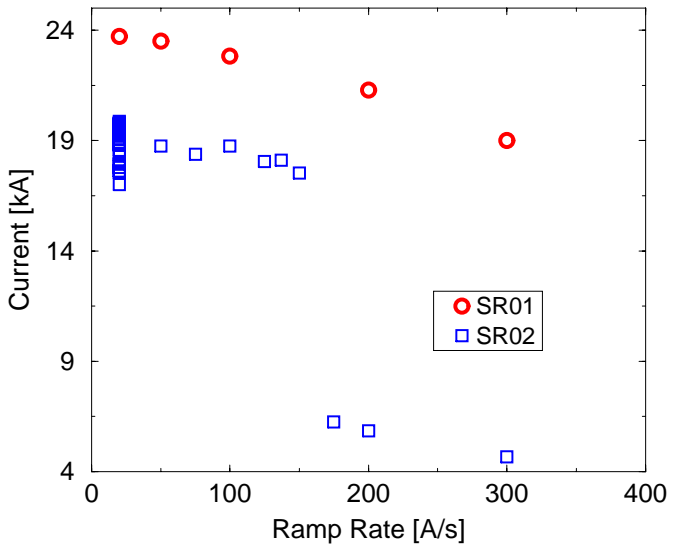

Fig. 6. Ramp rate dependence of SR01 and SR02.

\section{CONCLUSIONS}

Two small racetracks were designed, built and successfully tested at Fermilab. SR01, which contains PIT conductor, exhibited excellent performance. It reached its critical current limit within 14 quenches. PIT cable was used in our last costheta dipole model HFDA05 with reached its short sample limit at $10 \mathrm{~T}$ field [9]. SR02, with MJR conductor had moderately good performance. Its quench current plateau value was much higher than the quench current value of any other MJR based model magnet due to higher RRR value, but it didn't reach its high-field critical current limit, which is consistent with [8].

\section{ACKNOWLEDGMENT}

The authors thank LBNL magnet group for mechanical design and tooling drawings and assembly technology transfer and the staff of Fermilab's Technical Division who have worked hard on this effort over the course of the past year.

\section{REFERENCES}

[1] R. Hafalia et al., "A New Support Structure for High Field Magnets", IEEE Trans. Applied Superconductivity,vol. 12, No.1, March 2002.

[2] R. Hafalia et al.," An Approach for Faster high Fiel Magnet Technology Development”, IEEE Trans. Applied Superconductivity,vol. 13, No.2, June 2003.

[3] M.J. Lamm et al.,"A New Facility to Test Superconducting Accelerator Magnets", Proceedings of PAC'97, Vancouver, pp.3395-3397

[4] E.Barzi et al., "Sensitivity of Nb3Sn Rutherford-type cables to transverse pressure", submitted to this conference.

[5] V.V. Kashikhin, A.V. Zlobin, "Magnetic instabilities in Nb3Sn strands and cables", submitted to this conference.

[6] E. Barzi et al., "Transport Critical Current of Nb3Sn Strands at Low and High Magnetic Fields", submitted to this conference.

[7] G. Ambrosio et al., "Critical Current Measurement of $\mathrm{Nb}_{3}$ Sn Rutherfordtype Cables for High Field Accelerator Magnets",

[8] E. Barzi et al., "Study of Current Carrying Capability of Nb3Sn Cables in Self-field Using a SC Current Transformer", submitted to this conference.

[9] A.V. Zlobin et al., "Development and Test of Nb3Sn Cos-theta Dipoles Based on PIT Strands", submitted to this conference. 